\title{
Effect of Carbon Depth in Diminution of Physico-Chemical Pollution Parameters in Cassava Processing Wastewater Treated by Aeration-Peroxide Oxidation Method
}

\author{
Olayinka Omotosho ${ }^{1,}$, , Gbolabo Ogunwande ${ }^{2}$, Jimmy Osunbitan ${ }^{2}$ \\ ${ }^{1}$ Agricultural Engineering and Environmental Unit, Institute of Agricultural Research and Training, Obafemi Awolowo University, Moor \\ Plantation, Ibadan, Nigeria \\ ${ }^{2}$ Department of Agricultural and Environmental Engineering, Faculty of Technology, Obafemi Awolowo University, Ile-ife, Nigeria
}

Email address:

akintoshforever@gmail.com(O. Omotosho)

${ }^{*}$ Corresponding author

To cite this article:

Olayinka Omotosho, Gbolabo Ogunwande, Jimmy Osunbitan. Effect of Carbon Depth in Diminution of Physico-Chemical Pollution Parameters in Cassava Processing Wastewater Treated by Aeration-Peroxide Oxidation Method. Bioprocess Engineering.

Vol. 2, No. 1, 2018, pp. 10-13. doi: 10.11648/j.be.20180201.13

Received: February 28, 2018; Accepted: March 19, 2018; Published: April 10, 2018

\begin{abstract}
This study investigated the effect (attenuation of physico-chemical pollution characteristics) of carbon depth in vertical flow adsorption-filter system of the peroxide oxidation-aeration treatment process for cassava wastewater treatment. Results revealed that although the combined peroxide oxidation, aeration and adsorption-filter treatment process was successful in the reducing pollution characteristics of wastewater from cassava processing, the adsorption-filter part of the treatment process with carbon depths $0,5,10$ and $15 \mathrm{~cm}$ carbon depths were observed to have been selective in removal of physico-chemical pollution characteristics. Parameters such as colour, $\mathrm{SO}_{4}{ }^{2-}, \mathrm{NO}^{3-}, \mathrm{Cl}^{-}, \mathrm{Ca}^{2+}, \mathrm{Zn}^{2+}, \mathrm{TDS}$ and TSS were observed to have exhibited increased decontamination efficiency as the depth of carbon increased in the treatment process while $\mathrm{Fe}^{2+}$ and $\mathrm{CN}$ ions exhibited delayed adsorption. Depth of carbon filter was however observed to have had no effect on $\mathrm{Ni}^{2+}$ and Phenol content removal.
\end{abstract}

Keywords: Decontamination, Hydrogen Peroxide, Wastewater, Cassava, Aeration, Filtration

\section{Introduction}

Water is perhaps the most essential tangible substance required for sustenance of life on earth. However, it is not readily available in some regions due to climatic conditions while in other areas it exists in contaminated form [1]. In most situations the origin of water pollution has been linked to anthropogenic factors. [2] observed that water represents the most abused, poorly managed and polluted resource by human activities. Research has shown that although Africa has about 5 trillion $\mathrm{m}^{3}$ of fresh water resources available annually, only $3.8 \%$ of this supply has been developed, leaving 300 million Africans without access to safe drinking water [3]. This situation has been noted to be endemic in most parts of sub Saharan Africa particularly, Sudan, Chad, Niger and Nigeria where majority of their populations are resident in the rural areas and are dependent on seasonal water supply sources such as rivers, streams and ponds. One of the numerous sources of surface and groundwater pollution in developing countries is cassava processing industries. According to [4], these industries have been observed to discharge their effluent indiscriminately into nearby water courses as well as land thereby polluting surface and groundwater sources. In addition, [5] opined that the scale of production determines the level of pollution thus, large-scale processing if left unchecked will have the largest impact on the environment. It is therefore important to ensure that the limited water resources available is adequately preserved, thus the reduction of land and water pollution by effluent from cassava processing communities is essential. To this end, the study focused on the effectiveness of a three staged treatment process in the decontamination of physicochemical pollution agents in effluent from cassava processing activities. 


\section{Materials and Methods}

A three staged treatment process (Figure 1) consisting of a peroxide oxidation, aeration and simultaneous filtration and adsorption-filtration processes was used in the treatment of effluent collected from a cassava processing mill. The treatment set up was sited at the Department of Agricultural and Environmental Engineering, Obafemi Awolowo University, Ile-Ife, Nigeria.

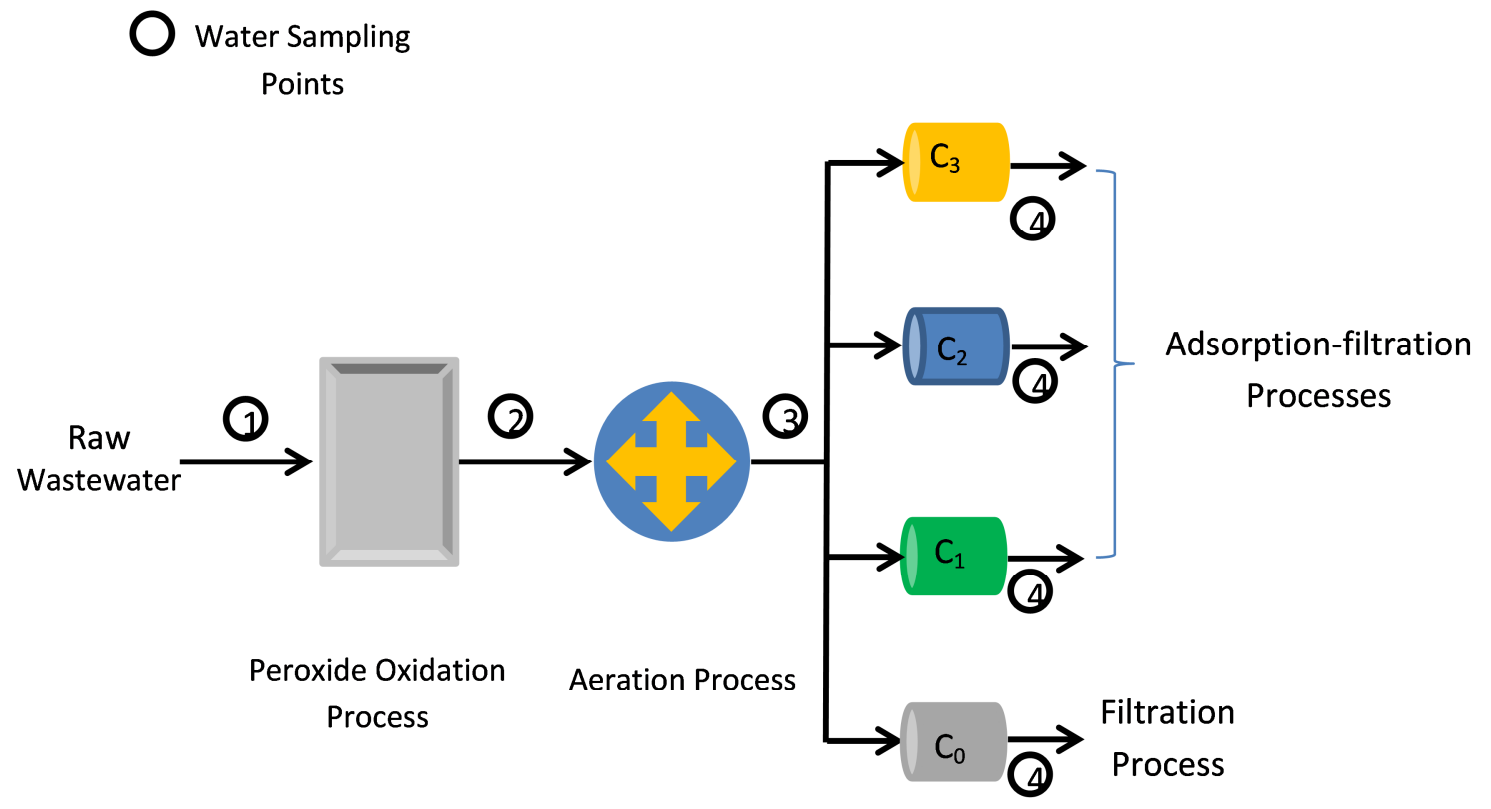

Figure 1. Flow diagram for three staged treatment process.

\subsection{Collection of Effluent for Treatment}

A 40 litre sample of effluent from a commercial cassava processing plant was obtained in opaque plastic material and kept under ice while transporting to the treatment site. This was to ensure that the condition of the wastewater at source was maintained after transportation as recommended by the [6].

\subsection{Peroxide Oxidation Process}

The $\mathrm{pH}$ of the collected wastewater was adjusted to a range between 10 and 11 by adding $0.5 \mathrm{M}$ of sodium hydroxide; hydrogen peroxide at $50 \%$ concentration was then added at $0.025 \mathrm{ml} / 1$ of wastewater (about $0.5 \mathrm{~g} \mathrm{H}_{2} \mathrm{O}_{2} / \mathrm{g}$ of $\mathrm{CN}^{-}$ ) for the oxidation process. The wastewater was thereafter left for a period of $3 \mathrm{~h}$ to ensure a reasonable level of oxidation and cyanide destruction. A sample of the effluent from the aeration chamber was obtained in a clean sterilised PET bottle and stored in an ice bucket to preserve it until end of the treatment process.

\subsection{Aeration Process}

The oxidised wastewater was then taken through aeration in a specially designed agitator with water displacement mechanism for a period of one hour. The effluent in the chamber was displaced by fresh effluent which was introduced from the inlet of the aeration chamber at a rate of $0.25 \mathrm{l} / \mathrm{min}$. The flow rate was carefully monitored to ensure that the system does not become overloaded. A sample of the effluent from the aeration chamber was obtained in a clean sterilised PET bottle and also stored in an ice bucket to preserve it until end of the treatment process.

\subsection{Filtration and Adsorption-Filtration Processes}

The oxidized-aerated wastewater was then introduced into the control sand filter column $\left(\mathrm{C}_{0}\right)$ of length $65 \mathrm{~cm}$. The oxidized-aerated wastewater was also introduced into three dual filter media columns at a flowrate of $1.0 \times 10^{-2} \mathrm{l} / \mathrm{s}$ as recommended for intermediate slow sand filter media by [7]. The configuration of the dual filter media were;

i. $\mathrm{C}_{1}=50 \mathrm{~cm}$ sand followed by $5 \mathrm{~cm}$ carbon followed by $10 \mathrm{~cm}$ sand.

ii. $\mathrm{C}_{2}=45 \mathrm{~cm}$ sand followed by $10 \mathrm{~cm}$ carbon followed by $10 \mathrm{~cm}$ sand.

iii. $\mathrm{C}_{3}=40 \mathrm{~cm}$ sand followed by $15 \mathrm{~cm}$ carbon followed by $10 \mathrm{~cm}$ sand.

Filtrates collected from filtration and adsorption filtration treatments were stored in clean sterilized PET bottles then kept in an ice bucket for preservation before analysis.

\subsection{Water Analysis}

The water samples collected from the sampling points as indicated in figure 1 were analysed using appropriate methods. Physical parameters such as colour, Total Suspended Solids (TSS), Total Dissolved Solids (TDS), were determined in accordance with $\mathrm{WHO} / \mathrm{EC}$ combined standards, following the methods described by [8]. The analysis of cyanide content of the water was carried out with the aid of a spectrophotometer (Spectrumlab 23A) using the alkaline picrate method. The sample was first be subjected to 
centrifuging at the speed of 4,200 rpm for about $6 \mathrm{~min}$. The obtained clear supernatant was separated and used for the test using a spectrophotometer at the recommended wavelength and $\mathrm{pH}$ range. Blanks which contained pure distilled water were also placed together with the samples in the spectrophotometer; these were used for calibration and quality check. Other chemical parameters such as light and heavy metals like Cadmium (Cd), Zinc (Zn), Nitrogen (N), Chlorine (Cl), Phosphorus (P), Iron (Fe), Nickel (Ni), Magnesium $(\mathrm{Mg})$, Manganese $(\mathrm{Mn})$, Mercury $(\mathrm{Hg})$ and Calcium $(\mathrm{Ca})$ were also determined by spectrophotometry using AAS machine with $\mathrm{HNO}_{3}$ as the reagent.

\subsection{Process decontamination Efficiency}

The decontamination efficiency is a measure of effectiveness of a treatment process in removal of a given parameter from the wastewater. This was calculated using the formula given in equation 1 as recommended by [9].

$$
D_{\%}=\frac{C_{i}-C_{f}}{C_{i}} \times 100
$$

Where $D_{\%}$ is the percentage decontamination, $C_{i}$ is the initial concentration of parameter in wastewater $\left(\mathrm{mg} \mathrm{l}^{-1}\right), \mathrm{C}_{\mathrm{f}}$ is the final concentration of parameter in treated wastewater $\left(\mathrm{mg} \mathrm{l}^{-1}\right)$.

\section{Results and Discussion}

\subsection{Decontamination Efficiency}

Analysis of the result obtained from the treatment process revealed that the decontamination efficiency (Table 1) for the treatment lines with adsorption-filter columns exhibited selective adsorption for the observed parameters. Parameters such as colour, $\mathrm{SO}_{4}{ }^{2-}, \mathrm{NO}^{3-}, \mathrm{Cl}, \mathrm{Ca}, \mathrm{Zn}, \mathrm{TDS}$ and TSS were observed to have exhibited increased decontamination efficiency as the depth of carbon increased in the treatment process. This trend may have been due to the effect of increased contact with active sites on the carbon material as observed by [10]. The carbon material in the treatment process was observed to have exhibited delayed adsorption of $\mathrm{Fe}$ and $\mathrm{CN}$ as concentration of effluent drawn from $\mathrm{C}_{0}$ and $\mathrm{C}_{1}$ were observed to be equal while increase was observed for $\mathrm{C}_{3}$ and $\mathrm{C}_{4}$ treatments. However parameters such as $\mathrm{Ni}^{2+}$ and Phenol content of the oxidized-aerated wastewater were not affected by the depth of carbon present in the treatment process.

Table 1. Decontamination efficiency of the control and treatment lines.

\begin{tabular}{lllll}
\hline \multirow{2}{*}{ Parameter* } & \multicolumn{4}{l}{ Decontamination Efficiency (\%) } \\
\cline { 2 - 5 } & $\mathbf{C}_{\mathbf{0}}$ & $\mathbf{C}_{\mathbf{1}}$ & $\mathbf{C}_{\mathbf{2}}$ & $\mathbf{C}_{\mathbf{3}}$ \\
\hline Colour (Lovibond units) & 35.0 & 46.5 & 52.0 & 57.4 \\
$\mathrm{Mg}^{2+}$ & 34.8 & 40.7 & 48.2 & 48.2 \\
$\mathrm{CN}^{-}$ & 95.0 & 95.0 & 100.0 & 100.0 \\
$\mathrm{SO}_{4}{ }^{2-}$ & 74.6 & 84.5 & 85.8 & 86.1 \\
$\mathrm{NO}^{3-}$ & 74.1 & 80.0 & 85.2 & 87.6 \\
$\mathrm{Fe}^{2+}$ & 41.2 & 41.2 & 44.7 & 49.4 \\
$\mathrm{PO}_{4}{ }^{3-}$ & 74.2 & 82.5 & 82.5 & 86.6 \\
\hline
\end{tabular}

\begin{tabular}{lllll}
\hline \multirow{2}{*}{ Parameter* } & \multicolumn{4}{l}{ Decontamination Efficiency (\%) } \\
\cline { 2 - 5 } & $\mathbf{C}_{\mathbf{0}}$ & $\mathbf{C}_{\mathbf{1}}$ & $\mathbf{C}_{\mathbf{2}}$ & $\mathbf{C}_{\mathbf{3}}$ \\
\hline $\mathrm{Mn}^{2+}$ & 60.0 & 60.0 & 60.0 & 80.0 \\
$\mathrm{Cl}^{-}$ & 52.4 & 57.6 & 59.7 & 60.6 \\
$\mathrm{Cd}^{2+}$ & 50.0 & 75.0 & 75.0 & 75.0 \\
$\mathrm{Ni}^{2+}$ & 75.0 & 75.0 & 75.0 & 75.0 \\
$\mathrm{Ca}^{2+}$ & 70.4 & 71.3 & 71.5 & 72.2 \\
$\mathrm{Zn}^{2+}$ & 54.9 & 54.9 & 54.9 & 63.4 \\
$\mathrm{Phenol}$ & 100.0 & 100.0 & 100.0 & 100.0 \\
$\mathrm{TDS}$ & 1.4 & 67.0 & 68.5 & 82.4 \\
$\mathrm{TSS}$ & 45.5 & 56.9 & 60.5 & 62.6 \\
\hline
\end{tabular}

* All units are in mg/l except where otherwise stated.

The presence of cyanide in water bodies has been observed to produce inimical side effects on the sustenance of aquatic life and biodiversity. It has been reported [11] that presence of cyanide inhibits the mitochondrial enzyme cytochrome oxidase in the respiratory electron transport chain, thus impairing both oxidative metabolism and the associated processes of oxidative phosphorylation in aquatic animals. The effluent drawn from the treatment processes as revealed in Table 2 were all below the FEPA/NESREA standards for cyanide discharge to water course.

\subsection{Treatment Effectiveness in Abatement of Effluent Pollution Characteristics}

According to [12], high level of nitrate in water has been known to induce methaeamoglobinaemia (Blue baby Syndrome) in infants less than 6 months old as well as infection diseases such as cyanosis and cancer of the alimentary canal. Nitrate pollution has also been known to cause environmental problems like eutrophication of waterbodies. Phosphates on the other hand are considered as the growth limiting nutrient for plants and microbial growth [13]. They are responsible for controlling freshwater and terrestrial ecosystems productivity [14]. From the Table 2 which shows the summary of results for effectiveness of the treatment in decontamination for the physico-chemical parameters considered, it can be observed that the concentration of phosphate and nitrate ions in the effluent from the four treatment processes were below the FEPA/NESREA standard for discharge to watercourse.

Suspended solids by nature are unsettled solid materials in water which can be trapped by passing through a filter or precipitated, thus high concentrations of suspended solids can cause many problems for stream health and aquatic life. [15] observed that the delivery of excessive levels of suspended solids into waterbodies can have significant deleterious impacts on the physical, chemical and biological properties of the waterbody. The TSS concentration values of effluents drawn from the treatment lines (Table 2) were observed to be above the FEPA/NESREA standards for discharge to waterbodies. This implies that there is a need for some form of additional treatment stage aimed at mitigating this issue. All other considered parameters were however observed to have been below the FEPA/NESREA standards for discharge to waterbodies. 
Table 2. Summary of treatment process effectiveness in abatement of effluent pollution characteristics for the four treatment lines.

\begin{tabular}{llllll}
\hline Parameter* & FEPA/NESREA Standard & $\mathbf{C}_{\mathbf{0}}$ & $\mathbf{C}_{\mathbf{1}}$ & $\mathbf{C}_{\mathbf{2}}$ & $\mathbf{C}_{\mathbf{3}}$ \\
\hline Colour $^{m}$ & 7 & $\sqrt{ }$ & $\sqrt{ }$ & $\sqrt{ }$ & $\sqrt{ }$ \\
$\mathrm{Mg}^{2+}$ & 200 & $\sqrt{ }$ & $\sqrt{ }$ & $\sqrt{ }$ & $\sqrt{ }$ \\
$\mathrm{CN}^{-}$ & 0.1 & $\sqrt{ }$ & $\sqrt{ }$ & $\sqrt{ }$ & $\sqrt{ }$ \\
$\mathrm{SO}_{4}{ }^{2-}$ & 500 & $\sqrt{ }$ & $\sqrt{ }$ & $\sqrt{ }$ & $\sqrt{ }$ \\
$\mathrm{NO}^{3-}$ & 20 & $\sqrt{ }$ & $\sqrt{ }$ & $\sqrt{ }$ & $\sqrt{ }$ \\
$\mathrm{Fe}^{2+}$ & 20 & $\sqrt{ }$ & $\sqrt{ }$ & $\sqrt{ }$ & $\sqrt{ }$ \\
$\mathrm{PO}_{4}{ }^{3-}$ & 5 & $\sqrt{ }$ & $\sqrt{ }$ & $\sqrt{ }$ & $\sqrt{ }$ \\
$\mathrm{Mn}^{2+}$ & 5 & $\sqrt{ }$ & $\sqrt{ }$ & $\sqrt{ }$ & $\sqrt{ }$ \\
$\mathrm{Cl}^{-}$ & 600 & $\sqrt{ }$ & $\sqrt{ }$ & $\sqrt{ }$ & $\sqrt{ }$ \\
$\mathrm{Cd}^{2+}$ & $<1$ & $\sqrt{ }$ & $\sqrt{ }$ & $\sqrt{ }$ & $\sqrt{ }$ \\
$\mathrm{Ni}^{2+}$ & $<1$ & $\sqrt{ }$ & $\sqrt{ }$ & $\sqrt{ }$ & $\sqrt{ }$ \\
$\mathrm{Ca}^{2+}$ & 200 & $\sqrt{ }$ & $\sqrt{ }$ & $\sqrt{ }$ & $\sqrt{ }$ \\
$\mathrm{Zn}^{2+}$ & $<1$ & $\sqrt{ }$ & $\sqrt{ }$ & $\sqrt{ }$ & $\sqrt{ }$ \\
$\mathrm{Phenol}^{2+}$ & 0.2 & $\sqrt{ }$ & $\sqrt{ }$ & $\sqrt{ }$ & $\sqrt{ }$ \\
$\mathrm{TDS}$ & 2,000 & $\sqrt{ }$ & $\sqrt{ }$ & $\sqrt{ }$ & $\sqrt{ }$ \\
$\mathrm{TSS}$ & 30 & $\mathrm{X}$ & $\mathrm{X}$ & $\mathrm{X}$ & $\mathrm{X}$ \\
\hline
\end{tabular}

$\sqrt{ }$ Met FEPA's (NESREA) standard

* All units $\mathrm{mg} / \mathrm{l}$ unless otherwise stated

$X$ Did not meet FEPA'S (NESREA) standard

$m$ Lovibond Units

\section{Conclusion}

Although the combined peroxide oxidation, aeration and adsorption-filter treatment process was successful in the abatement of pollution characteristics of wastewater from cassava processing, the adsorption-filter part of the treatment process was observed to be selective in removal of physicochemical pollution characteristics. Depth of carbon was observed to have had no effect on $\mathrm{Ni}^{2+}$ and Phenol removal while the other parameters were affected.

\section{References}

[1] Sangodoyin, A. Y., Ajayi-Banji, A. A. Adsorption potentials of modified and unmodified bone and horn char in diminution of microbial mass of polluted water. EIJIST. 2014; 3 (3):110118.

[2] Fakayode S. O. Impact of industrial effluents on water quality of the receiving Alaro river in Ibadan, Nigeria, 2005; AJEAM 10:1-13.

[3] Behr, P. Looming water crisis", CQ Glo. Res. 2008; 2: 27-56.

[4] Omotosho, O. A., Sangodoyin A. Y. Production and utilization of cassava peel activated carbon in treatment of effluent from cassava processing industry. WPT 2013; 8 (2): 215-224.

[5] Osunbitan, J. A., Short term effects of cassava processing wastewater on some chemical properties of loamy sand soil in Nigeria. J. Soil Sci. Environ. Managt. 2012; 3 (6): 164-171.

[6] United States Geological Survey's National Field Manual for the Collection of Water-Quality Data. Cariton: USGS c2006 [cited January 2018]. Accessible from http://pubs.water.usgs.gov/twri9A/.

[7] FEPA/NESREA:National Interim Guidelines and Standards for Industrial Effluents, Gaseous Emissions and Hazardous Waste Management in Nigeria. Federal Environmental Protection Agency (Now National Environmental Standards and Regulatory Enforcement Agency). (1991).

[8] Ademoroti C. M. A. Standard Methods for Water and Effluents Analysis System. A practical text book for water analysis. Foludex Press Limited, Ibadan, Nigeria: 1996. p. 2148.

[9] Ajayi-Banji, A. A., Ewemoje, T. A. Ajimo, A. A. Efficacy of locust beans husk char in heavy metal sequestration. Environ. Res. Eng. Managt. 2015; 71 (4): 5-10.

[10] Ajayi-Banji, A. A., Ewemoje, T. A. Ajimo, A. A. Efficacy of locust beans husk char in heavy metal sequestration. Environ. Res. Eng. Managt. 2015; 71 (4): 5-10.

[11] Daya S., R. B., Walker, S., AnooPkumar, D. Cyanide-Induced Free Radical Production and Lipid Peroxidation in Rat Brain Homogenate Reduced by Aspirin. Met. Br. Dis. 2000; 15 (3): 203-210.

[12] Campbell D. M., Forbes, G. J. Public health medicine and drinking water in Scotland. International J. Environ. H. Res. 2004; 4: 86-92.

[13] Muñoz A., Mas Torres F., Estela J. M., Cerda V. Evaluation of spectrophotometric methods for determination of orthophosphates by sequential injection analysis. Anal. Chimica Acta 1997; 350: 21-29.

[14] Zhang, H, Davison, W., Gadi, R. Kobayashi, T. In Situ Measurement of Dissolved Phosphorous in Natural Waters Using DGT. Anal. Chimica Acta 1998; 370: 29-38.

[15] Bilotta, G. S. and Brazier, R. E. (2008). Understanding the influence of suspended solids on water quality and aquatic biota. Wat. Res. 2008; 42: 2849-2861. 